\title{
Lives of Writing
}

\author{
Charles Bazerman \\ University of California, USA
}

Writers change over time as they mature and engage in different experiences. They may learn new ways of seeing and assessing their situations and goals, expand their repertoire of resources, gain confidence, and become more adept at making and carrying out writing choices. Sometimes the changes go in opposite directions, towards restriction, inflexibility, or even deterioration. Writing trajectories are complex and ultimately highly individual.

Researchers for decades have been studying writers and the texts they produce at different stages in and beyond educational settings, but we are just starting see how these writers develop within lifelong trajectories of learning to write. It isn't easy to follow writers across years, so long-term longitudinal studies are few. It is even harder to keep track of writers as they move from one level of school to another and then follow them out into their workplaces and lives, so studies of how writing development at one level prepares students for the next stages of life are even fewer. Even harder is to collect details of perceptions, thinking, and choices as writers grow over their lives. So, while we now know many pieces of writers' situations, products, and processes, we have little idea of how these add up to lives of writing (Bazerman, 2013, forthcoming).

Two recent books, one reviewed in this issue of Writing \& Pedagogy (Bazerman et al., 2018), and the other reviewed in the previous issue (Roozen and Erickson, 2017) attempt to address these difficulties through

\footnotetext{
Affiliation

University of California at Santa Barbara, 574 Calle Anzuelo, Santa Barbara, CA 93111, USA Email: bazerman@education.ucsb.edu
} 
both examination of broader principles to guide research and through presentation and comparison of multiple studies. These two volumes and other studies indicate that experiences before school, out of school during the school years and after school are often quite different than the experiences and teaching offered in school. Furthermore, experiences in different stages of schooling are themselves disjunct, even when there is multi-year curricular planning; we have, however, little information about students' strategies for handling these leaps and disjunctions, so it is not easy to see how these experiences add up and position the writer for series of writing challenges across their lives.

As we discover how individual and idiosyncratic each person's apprenticeship in writing is, we find that it is also difficult to analyze, synthesize, and generalize successfully across the individual cases we are collecting to be able to make aggregate statements about developmental processes. The greatest successes in this area are in emergent literacy as young children first address some of the basic understandings about literacy; here, nonetheless, we find still find individuality in sense-making processes, even as children move toward normalizing of behavior and forms of production.

With all this complexity, disjointedness, idiosyncrasy, and unpredictability in writing development, it has been hard to bring order to curriculum within and across levels, and we are still early in planning developmentally appropriate curricula. Teachers instead must address the students they find in their classrooms with all the complexities and differences of their separate trajectories. The alternatives are either to propose activities that may be doable but are haphazard in helping writers develop or to set writing tasks that are beyond the scope of many students and reward those students who don't drown.

We cannot let these questions of writing development go just because they are difficult. Development of writers, and not the collection of discrete skills and forms of correctness, are the heart of writing education, and all the evidence and understanding we can bring to development will have important consequences for how we approach and support students at all levels.

The good news is that more research is starting to take both developmental and longitudinal approaches, and in fact a Writing through the Lifespan Collaborative ${ }^{1}$ of over forty scholars in different countries has formed to advance this research. This special issue as well offers some important steps in this direction. The studies reported here look at different moments in writing, three looking at different levels of schooling one synoptically examining studies across different ages. Moreover these studies highlight the importance of setting for the challenges and experiences developing writers face. Together they highlight the complexity and 
variety of writing development. It is worth noting that given the challenges of engaging in this work that three of the four articles here are the work of collaborative teams is the book reviewed.

The first article, 'Writing development and education standards in crossnational perspective' by Jill Jeffery, Nikolaj Elf, Gustaf Bernhard Skar, and Kristen Campbell Wilcox, compares the differences of writing curricula in the US, Denmark, and Norway. The second, 'Creating accounts of diverse developmental writing paths within a Colombian major in industrial engineering' by Elizabeth Narvaez looks at undergraduate writing experiences in Colombia incorporating industrial internships within hybrid assignments. The third 'Researching writing across the lifespan: The value of literacy studies for highlighting social and contextual aspects of change' by Karin Tusting, David Barton, Sharon McCulloch, Uta Papen, and Diane Potts synthesizes multiple studies of postgraduate students at a British university. Finally 'In transition: Researching the writing development of doctoral students and faculty' by Sandra Tarabochia and Shannon Madden compares the differing writing concerns of graduate students and early career professors at research universities in the US. The issue concludes with a review of the first of the two previously mentioned recent books.

So here we have a few focused pictures of developing writers and writing education from different regions and stages of education. Of course, we need many more studies in many different settings to start to fill in a picture and find patterns, yet from these four we can begin to see some big themes.

First and foremost, context matters. In these studies we see context including such varied elements as the national culture and policies, social institutional setting, and the specific activity system and genres the writer is engaged in. Context also includes the new technologies that change the means of writing and distribution as they provide both learning challenges and opportunities for supporting and extending writing, as is highlighted in the Tusting et al. studies.

But context also includes personal factors such as the particular histories of the writers and the particular stage of their development. For example, in the Tarabochia and Madden study, the main variable of difference between the two groups of scholars was whether they had completed their doctorates and obtained regular positions. Otherwise they were located in similar institutions and engaged in similar research and publication tasks. Yet while both groups were attentive to institutional structures, the doctoral students were concerned with the structure of their departments, and the emerging scholars were concerned with the structure of the profession. Further, the doctoral students were more concerned with mentorship, while the emerging scholars were more concerned with building 
professional identities. We could say that not only were they attentive to different parts of their context and their relationships to those contexts, but their very ideas about where the relevant context was differed.

What people are attentive to indicates what problems they are solving and thus where they are developing. Further the attention to new writing positions, issues, and challenges raises fundamental and affect-saturated questions of who the writers are, as we see in the studies of writers in transition in both the Tusting et al. and Tarabochia and Madden articles. How they are developing as writers is closely tied to how they are developing as people.

While curricular guidelines and institutional demands define goals for learning and development, they do not mean that students will learn what is expected or in the way expected, or even that teachers will even present the curriculum in the same way. Nonetheless, curricular guidelines and institutional expectations do create conditions and opportunities for learning, as well as offer possible stances and attitudes for writers. The Jeffery et al. comparative study of secondary school curricula in Denmark, Norway, and the US highlights the importance of institutional sponsorship for determining opportunities made available to students. Norwegian standards attempt to build diversity and flexibility in writing, while Danish and US standards direct students towards analytic, disciplinary writing, but with some differences of definition and emphases.

What is presented for developing writers may contain as well puzzles and contradictions that may impede or confuse learning, as we see in the case of the Colombian students studied by Narvaez. In this case industrial engineering students are asked to engage in different kinds of writing, with little coherence or sequence in their writing experiences, leaving them without adequate preparation for their final year projects. This incoherence is further exacerbated by the different expectations of the workplace internship which forms the nominal tasks and the academic expectations of the university setting where the work is evaluated.

Our writing lives are filled with disjunctions, leaps, miraculous learning and painful failures - and sometimes helpful experiences that bring our accomplishments closer to our intentions. Historically, those who have succeeded in the journey have been so few as to be seen as having unexplainable talents or even magical powers. The more we can understand the pathways to competence and satisfaction, the more we can facilitate access for all to the power of writing. 


\section{About the author}

Charles Bazerman is affiliated to the Department of Education, Gevirtz Graduate School of Education, University of California, Santa Barbara Santa Barbara, CA USA.

\section{Note}

1 https://ryan-dippre.squarespace.com/

\section{References}

Bazerman, C. (2013). Comprendiendo de un viaje que dura toda la vida: la evolución de la escritura. Understanding the lifelong journey of writing development. Revista Infancia y Aprendizaje/Journal for the Study of Education and Development 36 (4), 421-441.

Bazerman, C. (forthcoming). The puzzle of conducting research on lifespan development of writing. In C. Donahue (Ed.). Writing Research Methods and Methodologies: 50 Years from the Dartmouth Seminar.

Bazerman, C., Applebee, A., Berninger, V., Brandt, D. Graham, S., Jeffery, J. V., Matsuda, P. K., Murphy, S., Rowe, D., Schleppegrell, M. and Wilcox, K. (2018). Lifespan Development of Writing Abilities. Urbana, IL: NCTE Press.

Roozen, K. and Erickson, J. (2017). Expanding Literate Landscapes: Persons, Practices, and Sociohistoric Perspectives of Disciplinary Development Computers and Composition Digital P/Utah State UP. http://ccdigitalpress.org/expanding 
